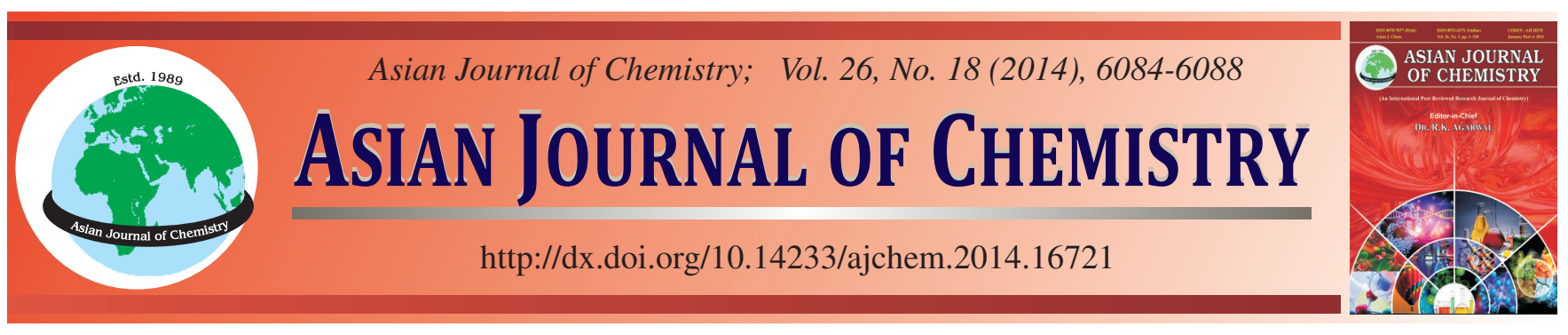

\title{
Spectrophotometric Determination of Monosaccharide Composition of Wood (Pinus brutia Ten.) Using Artificial Neural Network Modelling
}

\author{
SAMIM YASAR
}

Department of Forest Products Engineering, Faculty of Forestry, Suleyman Demirel University, 32260-Isparta, Turkey

Corresponding author: Fax: +90 246 2371810; Tel: +90 246 2113973, E-mail: samimyasar@ sdu.edu.tr

Spectrophotometric data were used to estimate monosaccharide content in Pinus brutia Ten. (brutian pine) wood using artificial neural network (ANN) modelling. The monosaccharide composition of $P$. brutia Ten. samples ranged for glucose from 42.33 to $54.67 \%$, for mannose from 8.55 to $11.95 \%$, for xylose from 7.15 to $9.83 \%$, for galactose from 1.72 to $2.49 \%$ and for arabinose from 1.19 to $1.65 \%$, based on extractive free dry wood. Three layered artificial neural network model with six hidden neurons gave in general better results with correlation $\mathrm{R}^{2}$ values between 0.9987 and 0.9916 in training and between 0.9984 and 0.9902 in testing. In validation, this model was scored with a small average relative error (1.2\%) fairly good.

Keywords: Pinus brutia Ten., Monosaccharide composition, Spectrophotometric data, Artificial neural network.

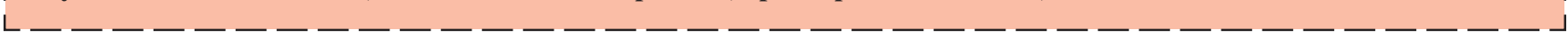

\section{INTRODUCTION}

Wood polysaccharides are composed of two main components i.e., cellulose and polyoses (hemicelluloses) ${ }^{1}$. Besides usage in paper, rayon or cellulose derivates production as main component, cellulose is an important raw material after conversation in to glucose. Polyoses are also hydrolyzed to different monosaccharides. Main utilization of wood monosaccharides including glucose, mannose, xylose, galactose, arabinose and rhamnose is to produce other chemicals ${ }^{1-7}$.

The anthrone method is an ordinary spectrophotometric procedure and applied for total sugar determination. This procedure can be used rapid and cost effective to analyze various samples. Anthrone substituted hexoses produce a blue colour and pentoses a yellow-green colour in the solution ${ }^{8}$. This produced colour has a spectrophotometric response which is compared to a curve based on a standard (in general glucose) to determine the total sugar amount in the hexose solutions or the solutions rich in hexose ${ }^{9-17}$.

In the previous studies, spectral data were used to determine the carbohydrate contents of Pinus radiata using Partial Least Squares (PLS) ${ }^{18}$, the monosaccharide composition of Eucalyptus globulus using PLS data analysis method ${ }^{19}$ and the hexose and pentose amounts using artificial neural network $(\mathrm{ANN})^{20}$.

Artificial neural networks consist of neurons which are similar to their biological counterparts. The interconnections of neurons organized in different layers including input, hidden and output are computed with neural connection weights which can be modified during the training step of network. For weight optimization of network, the activation function and back propagation algorithm are utilized. The connection weights are adapted to minimize the error between the desired target data values and their predicted data values. After the weights have been determined, the performance of the network is checked on a test set for fixing the network accuracy in predicting external data sets. This procedure is repeated for various networks to obtain an optimum artificial neural network structure $^{21-30}$.

In this study, quick and easily estimation of Pinus brutia Ten. (brutian pine) sugar composition which consist of heterogeneous monosaccharides (hexoses and pentoses) including glucose, mannose, xylose, galactose and arabinose was aimed. UV-visible spectra from anthron substituted monosaccharides were collected and from these spectra, monosaccharide composition of $P$. brutia Ten. was estimated using artificial neural network modelling.

\section{EXPERIMENTAL}

The $P$. brutia Ten. samples were wood discs taken at 1.30 $\mathrm{m}$ height from 30-35 year-old trees from Asagi Gokdere-Isparta and Kas-Antalya in Turkey. The disc of each tree was debarked and chipped. After air drying, wood chips were separately ground to pass 40-100 mesh in Retsch SK 1 mill. The milled wood material was extracted with 2:1 cyclohexane:ethanol and 
followed by extraction with ethanol in Buchi extraction system B-811.

For acid hydrolysis, Pettersen et al..$^{31}$ method was used. $200 \mathrm{mg}$ extracted wood meal (on oven dry basis) were firstly hydrolyzed for $1 \mathrm{~h}$ at $30{ }^{\circ} \mathrm{C}$ in $72 \% \mathrm{H}_{2} \mathrm{SO}_{4}$, then diluted to $3 \%$ and secondly hydrolyzed for $1 \mathrm{~h}$ at $120{ }^{\circ} \mathrm{C}$ in P-Selecta autoclave. After filtering and washing the Klason lignin, the filtrate and washing water were transferred to $1 \mathrm{~L}$ volumetric flask. $0.5 \mathrm{~mL}$ of this solution was diluted to $1 \mathrm{~mL}$ by adding distilled water. $2 \mathrm{~mL}$ anthrone reagent $(200 \mathrm{mg}$ anthrone suspended in $100 \mathrm{~mL} 96-98 \% \mathrm{H}_{2} \mathrm{SO}_{4}$ ) were added to $1 \mathrm{~mL}$ solution of each sample. The solutions were submitted to a boiling water bath for $10 \mathrm{~min}^{11}$. After cooling, the spectra of solutions were recorded in Perkin Elmer Lambda $20 \mathrm{UV} /$ visible Spectrometer in the wave number range 190-900 nm. Five spectra per sample were collected. For each UV-visible spectrum, baseline was corrected and defined by connecting the absorbance value at 470 and $740 \mathrm{~nm}$ then 135 absorbance values (difference between value and the baseline) between 470 and $740 \mathrm{~nm}$ were used in the artificial neural network modelling.

From the $1 \mathrm{~L}$ acid hydrolyze solution, monosaccharide composition of each $P$. brutia Ten. sample was determined according to the gas chromatographic procedure of Cao et al. ${ }^{32}$ and expressed as percentage of oven dried extract-free material.

Artificial neural network models were employed using sigmoidal logistic function with back propagation of error algorithm. 45, 15 and 10 data pairs were chosen randomly from the bottom, middle and top values of data and used for training, testing and validation sets, respectively. In a data pair (inputs-output), inputs composed of 135 points (absorbance values) between 470 and $740 \mathrm{~nm}$ from UV-visible spectrum of each sample as neurons in the input layer and outputs were glucose, mannose, xylose, galactose and arabinose amounts as five neurons in the output layer. Artificial neural networks were trained with different number of neurons in the hidden layer. The structure and the topology of used network are indicated in Figs. 1 and 2, respectively.

However, the logistic function was used as activation function in the network construction. Therefore, all data were normalized into a range 0.1-0.9 using equation 1 before presenting to artificial neural network.

$$
\mathrm{X}_{\mathrm{N}}=0.1+\frac{0.8\left(\mathrm{X}-\mathrm{X}_{\min }\right)}{\left(\mathrm{X}_{\max }-\mathrm{X}_{\min }\right)}
$$

$\mathrm{X}_{\mathrm{N}}$ : The normalized value of the input or the output data

$\mathrm{X}$ : Original value of the data

$\mathrm{X}_{\max }$ and $\mathrm{X}_{\min }$ : The maximum and the minimum original values of the data

The classification performance of trained network model is then evaluated on an introducing test set. The overall accuracy of the artificial neural network models was measured using root mean square (RMS) error by eqn. 2 below:

$$
\mathrm{RMS}=\sqrt{\mathrm{N}^{-1} \sum_{\mathrm{i}=1}^{\mathrm{N}}\left(\mathrm{X}_{\mathrm{i}}^{\mathrm{i}}-\mathrm{X}_{\mathrm{i}}\right)^{2}}
$$

$\mathrm{N}$ : The number of data

$\mathrm{X}$ 'i :The target value

$\mathrm{Xi}$ : The output value produced by the network
Determining the values of 135 independent variables

[The input data matrix $(135 \times 60)]$

Determining the values of 5 dependent variables

[The output data matrix $(5 \times 60)]$

\section{$\downarrow$}

Preparation of the training data set:

$\rightarrow$ [The input data matrix (135x45)]; [The output data matrix $(5 \times 45)]$ Preparation of the testing data set:

[The input data matrix $(135 \times 15)]$; [The output data matrix $(5 \times 15)]$

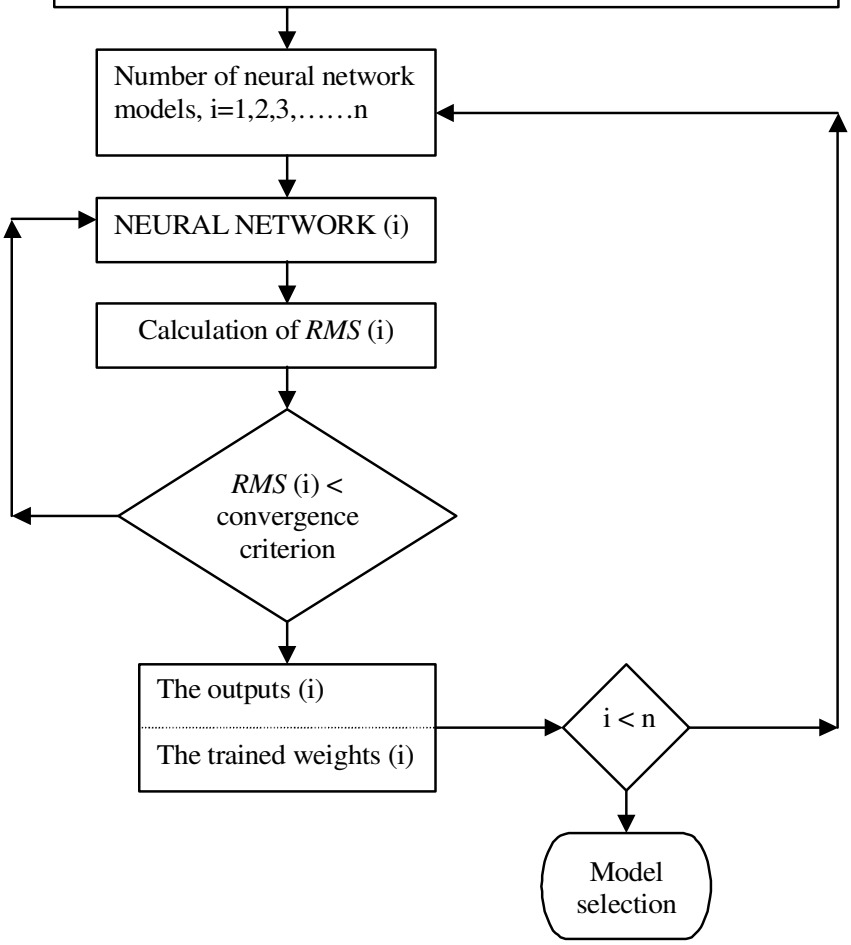

Fig. 1. Operational sequence of the artificial neural network (ANN) simulation method

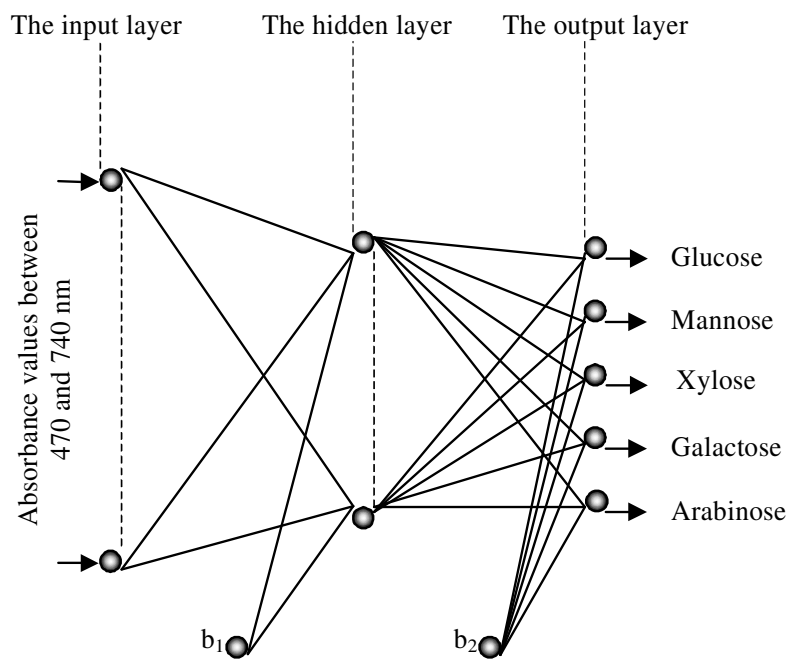

Fig. 2. Network architecture used for prediction of monosaccharide composition of $P$. brutia Ten. samples from UV-visible spectral data

\section{RESULTS AND DISCUSSION}

From the spectrophotometric measurements, absorbance values between 470 and $740 \mathrm{~nm}$ were used in the artificial neural network modelling after baseline correction (Fig. 3). 


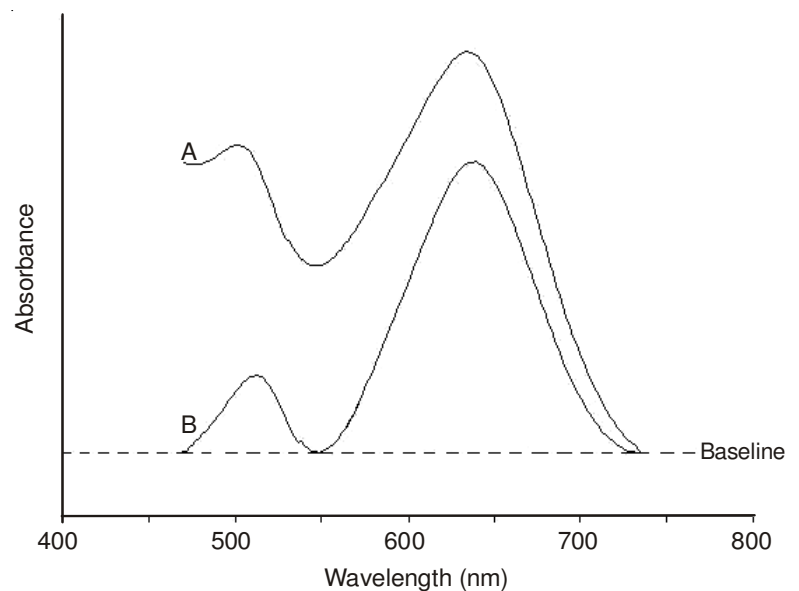

Fig. 3. UV-visible Spectrum of P. brutia Ten. sample A: Original spectrum B: Baseline corrected spectrum

Glucose, mannose, xylose, galactose and arabinose were determined as monosaccharides in P. brutia Ten. samples. Contents of monosaccharides are shown in Fig. 4. In the figure,



Fig. 4. Monosaccharide amounts of P. brutia Ten. samples (Glu: glucose, Man: mannose, Xyl: xylose, Gal: galactose and Ara: arabinose) amount of each monosaccharide was expressed as percentage of oven dried extract-free material. Glucose amounts were varied between 42.33-54.67, 42.41-54.45 and 42.86-54.28\%, Mannose amounts between 8.55-11.95, 8.58-11.85 and 8.65$11.84 \%$, xylose amounts between 7.15-9.83, 7.17-9.82 and 7.18-9.81\%, galactose amounts between 1.72-2.49, 1.77-2.44 and 1.8-2.42\%, arabinose amounts between 1.19-1.65, 1.21.64 and $1.21-1.62 \%$ in the training, testing and validation step of artificial neural network, respectively.

After training and testing, the number of hidden neurons of the network was obtained by evaluating the performance determined using RMS error of the network models (Table-1). The $\mathrm{NN}_{3}$ model with 6 hidden neurons was chosen to estimate the monosaccharide contents because the average RMS error for testing data sets was the lowest value.

Fig. 5 indicates the predicted values of monosaccharide contents from the $\mathrm{NN}_{3}$ model and the actual (target) values for the training data set by linear regression. The results showed that agreement between the predicted and the actual monosaccharide contents generally good with correlation $\mathrm{R}^{2}$ values of $0.9987,0.9984,0.9978,0.9916$ and 0.9964 , respectively.

$\mathrm{NN}_{3}$ model provided also good correlation between predicted and actual data in the testing. For glucose, mannose, xylose, galactose and arabinose, correlation coefficients $\left(\mathrm{R}^{2}\right)$ were fairly high and 0.9984, 0.9938, 0.9945, 0.9902 and 0.9949, respectively (Fig. 6).

To show validation of the model selected, the data pairs of 10 additional samples were used. Experimental and predicted results from the model NN3 were given in Table- 2 . As can be seen from the table, the predicted values were close to actual values of monosaccharide composition with an average per cent relative error of 1.2 .

In conclusion, the high correlation coefficients $\left(\mathrm{R}^{2}\right)$ in the training and testing and the low average relative error of prediction in the validation indicate that three layered artificial neural
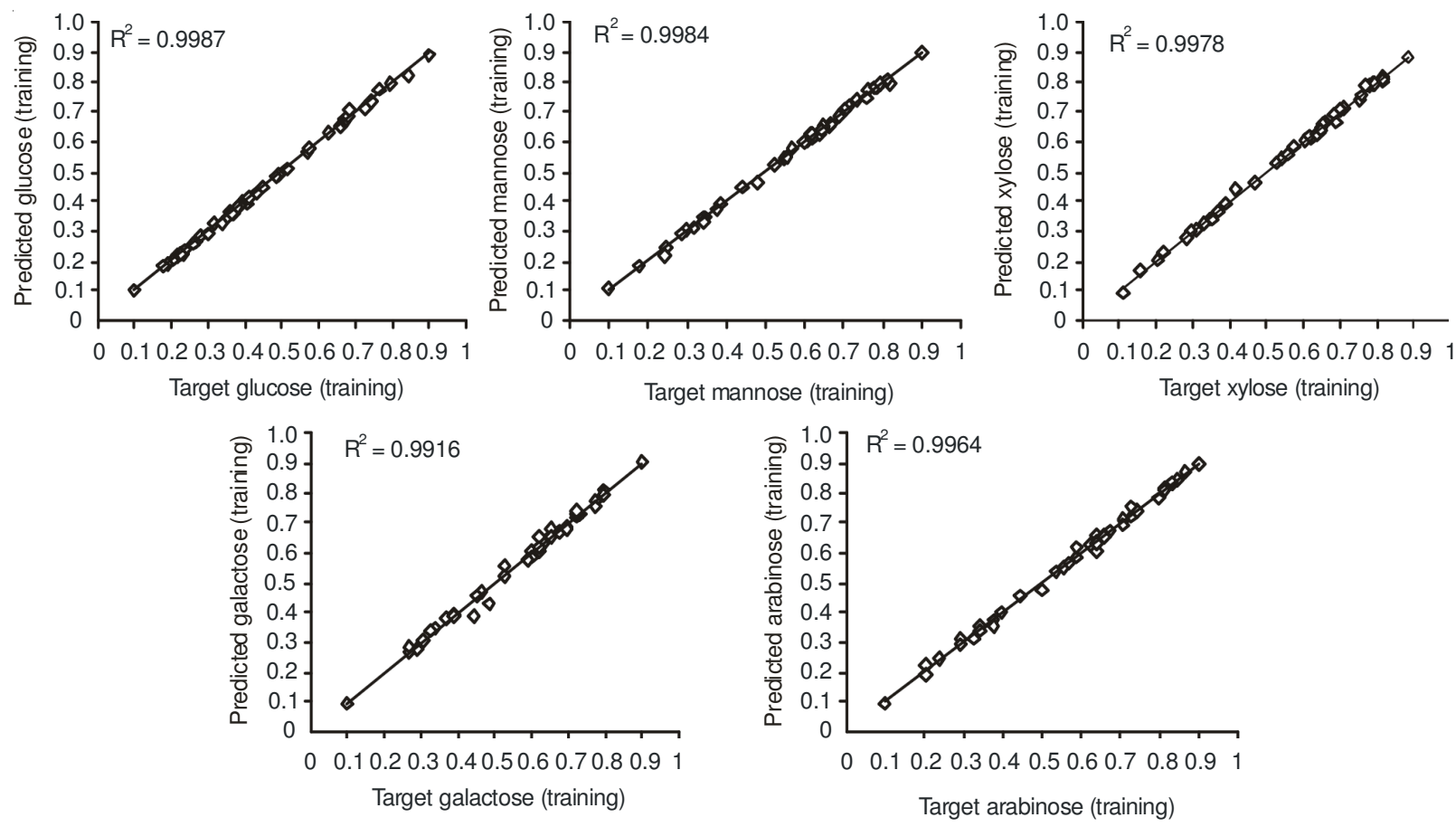

Fig. 5. Prediction performance of $\mathrm{NN}_{3}$ model for monosaccharide composition training data set 


\begin{tabular}{|c|c|c|c|c|c|}
\hline \multirow{3}{*}{ Model } & \multicolumn{4}{|c|}{$\begin{array}{c}\text { TABLE-1 } \\
\text { COMPARISON OF THE PERFORMANCES OF THE NETWORK MODELS }\end{array}$} & \\
\hline & \multicolumn{5}{|c|}{ RMS error } \\
\hline & Glu-training & Glu-testing & Man-training & Man-testing & Xyl-training \\
\hline NN1 135-2-5 & 0.009238 & 0.009707 & 0.008325 & 0.011267 & 0.01148 \\
\hline NN2 135-4-5 & 0.008849 & 0.012185 & 0.007921 & 0.010158 & 0.010701 \\
\hline NN3 135-6-5 & 0.007189 & 0.009534 & 0.00777 & 0.0175 & 0.009542 \\
\hline NN4 135-8-5 & 0.007483 & 0.113164 & 0.007225 & 0.173894 & 0.009322 \\
\hline \multirow[t]{2}{*}{ NN5 135-10-5 } & 0.006246 & 0.040356 & 0.007811 & 0.037284 & 0.007672 \\
\hline & Xyl-testing & Gal-training & Gal-testing & Ara-training & Ara-testing \\
\hline NN1 135-2-5 & 0.016922 & 0.035139 & 0.029277 & 0.018951 & 0.01519 \\
\hline NN2 135-4-5 & 0.016647 & 0.027799 & 0.037774 & 0.018327 & 0.014432 \\
\hline NN3 135-6-5 & 0.016848 & 0.016624 & 0.021082 & 0.012147 & 0.015748 \\
\hline NN4 135-8-5 & 0.217871 & 0.009992 & 0.325494 & 0.013815 & 0.214475 \\
\hline NN5 135-10-5 & 0.051963 & 0.014298 & 0.086908 & 0.008773 & 0.051045 \\
\hline
\end{tabular}
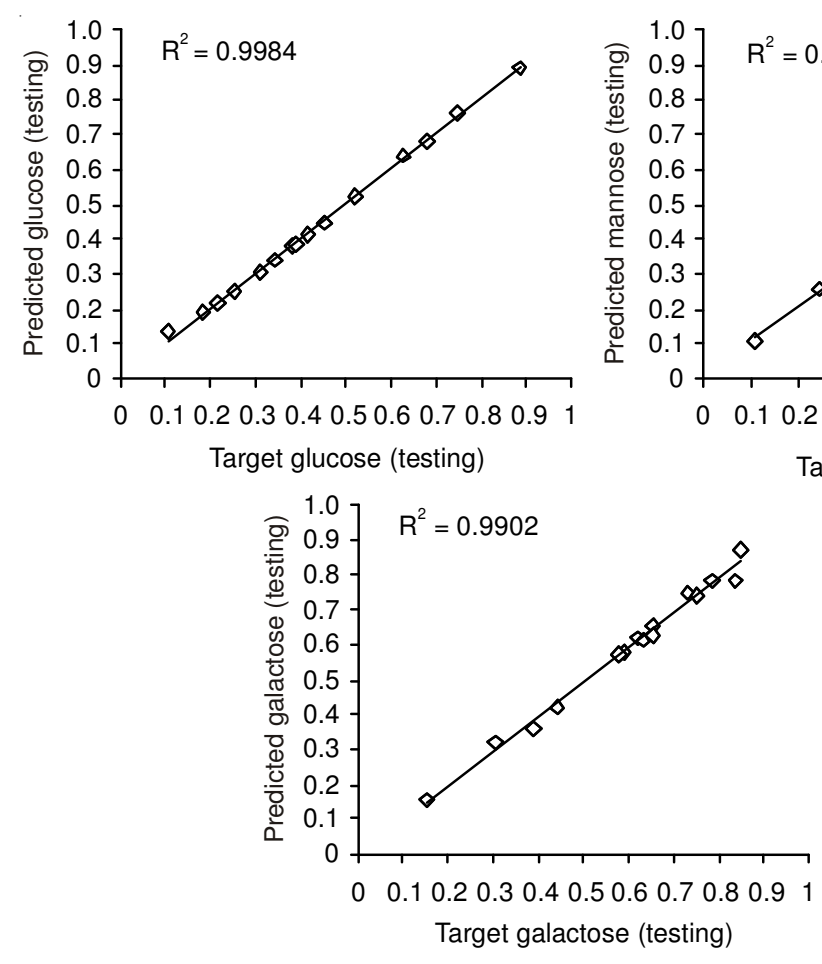

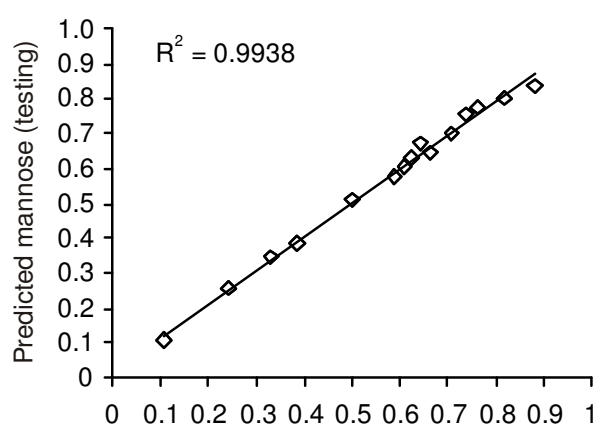

Target mannose (testing)
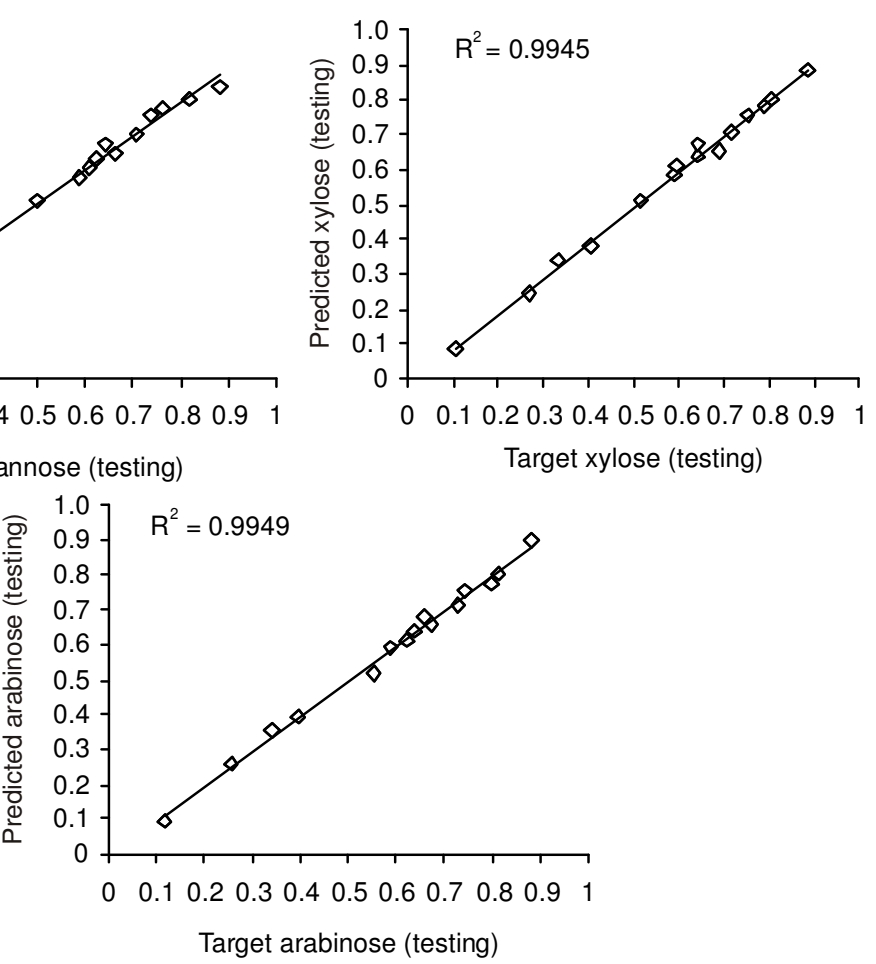

Fig. 6. Prediction performance of $\mathrm{NN}_{3}$ model for monosaccharide composition testing data set

\begin{tabular}{|c|c|c|c|c|c|c|c|c|c|c|c|c|c|c|c|}
\hline \multicolumn{16}{|c|}{$\begin{array}{c}\text { TABLE-2 } \\
\text { PERFORMANCE OF } \mathrm{NN}_{3} \text { MODEL IN THE VALIDATION STEP }\end{array}$} \\
\hline \multicolumn{16}{|c|}{ Monosaccharide composition (\%) } \\
\hline \multirow{2}{*}{ Sample } & \multicolumn{3}{|c|}{ Glucose } & \multicolumn{3}{|c|}{ Mannose } & \multicolumn{3}{|c|}{ Xylose } & \multicolumn{3}{|c|}{ Galactose } & \multicolumn{3}{|c|}{ Arabinose } \\
\hline & Actual & Predicted & RE \% & Actual & Predicted & RE \% & Actual & Predicted & RE \% & Actual & Predicted & RE \% & Actual & Predicted & RE \% \\
\hline 1 & 45.03 & 45.41 & 0.84 & 11.27 & 11.14 & -1.15 & 9.35 & 9.42 & 0.75 & 2.35 & 2.38 & 1.28 & 1.56 & 1.58 & 1.28 \\
\hline 2 & 46.20 & 46.08 & -0.26 & 10.97 & 11.25 & 2.55 & 9.19 & 9.06 & -1.41 & 2.26 & 2.24 & -0.88 & 1.53 & 1.52 & -0.65 \\
\hline 3 & 47.42 & 46.97 & -0.95 & 10.64 & 10.33 & -2.91 & 8.84 & 8.89 & 0.57 & 2.12 & 2.10 & -0.94 & 1.48 & 1.46 & -1.35 \\
\hline 4 & 42.86 & 42.75 & -0.26 & 11.84 & 11.99 & 1.27 & 9.81 & 9.69 & -1.22 & 2.41 & 2.45 & 1.66 & 1.62 & 1.64 & 1.23 \\
\hline 5 & 46.90 & 47.28 & 0.81 & 10.73 & 10.52 & -1.96 & 8.81 & 8.97 & 1.82 & 2.21 & 2.19 & -0.90 & 1.49 & 1.51 & 1.34 \\
\hline 6 & 44.08 & 44.27 & 0.43 & 11.68 & 11.84 & 1.37 & 9.62 & 9.48 & -1.46 & 2.42 & 2.39 & -1.24 & 1.60 & 1.58 & -1.25 \\
\hline 7 & 49.69 & 49.96 & 0.54 & 9.89 & 9.68 & -2.12 & 8.20 & 8.35 & 1.83 & 2.04 & 2.02 & -0.98 & 1.38 & 1.40 & 1.45 \\
\hline 8 & 51.75 & 51.62 & -0.25 & 9.45 & 9.58 & 1.38 & 7.85 & 7.98 & 1.66 & 1.94 & 1.92 & -1.03 & 1.31 & 1.33 & 1.53 \\
\hline 9 & 54.28 & 54.64 & 0.66 & 8.65 & 8.44 & -2.43 & 7.18 & 7.11 & -0.97 & 1.80 & 1.78 & -1.11 & 1.21 & 1.19 & -1.65 \\
\hline 10 & 46.52 & 46.30 & -0.47 & 10.91 & 10.79 & -1.10 & 9.12 & 9.22 & 1.10 & 2.24 & 2.22 & -0.89 & 1.51 & 1.50 & -0.66 \\
\hline
\end{tabular}


network with 6 hidden neurons can properly model complex relationship between UV-visible spectral data and monosaccharide composition of $P$. brutia Ten. wood.

\section{REFERENCES}

1. D. Fengel and G. Wegener, Wood-Chemistry, Ultrastructure Reaction, Walter de Gruyter, Berlin (1984).

2. J. Lee, J. Biotechnol., 56, 1 (1997).

3. B.K. Ahring, D. Licht, A.S. Schmidt, P. Sommer and A.B. Thomsen, Bioresour. Technol., 68, 3 (1999).

4. J.N. Nigam, J. Biotechnol., 87, 17 (2001)

5. J. Robinson, J.D. Keating, S.D. Mansfield and J.N. Saddler, Enzyme Microb. Technol., 33, 757 (2003).

6. J. Söderström, L. Pilcher, M. Galbe and G. Zacchi, Biomass Bioenergy, 24, 475 (2003)

7. A. Sues, R. Millati, L. Edebo and M.J. Taherzadeh, FEMS Yeast Res., 5, 669 (2005).

8. W. Blaschek, in eds.: G. Franz, Polysaccharide, Springer Verlag, BerlinHeidelberg-New York, Chap. 2, pp. 17-47 (1992).

9. R. Li, J.J. Volenec, B.C. Joern and S.M. Cunningham, Crop Sci., 36, 617 (1996).

10. J. Moreno, C. Vargas-Garcia, M.J. Lopez and G. Sanchez-Serrano, J. Appl. Microbiol., 86, 439 (1999).

11. W. Praznik, N. Mundigler,A. Kogler,P. Huber,A. Huber and M. Wollendorfer, Starch/Stärke, 51, 197 (1999).

12. A.K.K. Achakzai and S.A. Kayani, Asian J. Plant Sci., 1, 618 (2002)

13. F.L. Consoli and S.B. Vinson, Comp. Biochem. Physiol. B, 132, 711 (2002).

14. A.K.K. Achakzai, S.A. Kayani, M. Yaqoob and A. Nabi, J. Biol. Sci., 3, 882 (2003).
15. A. Oren and L. Mana, FEMS Microbiol. Lett., 223, 83 (2003).

16. G.D. Manrique and F.M. Lajolo, Postharvest Biol. Technol., 33, 11 (2004).

17. L. Zhang, Z. Lu, Z. Yu and X. Gao, Food Contr., 16, 279 (2005).

18. R. Meder, S. Gallagher, K.L. Mackie, H. Bohler and R.R. Meglen, Holzforschung, 53, 261 (1999).

19. J. Rodrigues, J. Puls, O. Faix and H. Pereira, Holzforschung, 55, 265 (2001).

20. S. Yasar, Acta Chim. Slov., 52, 435 (2005).

21. J. Zupan and J. Gasteiger, Anal. Chim. Acta, 248, 1 (1991).

22. J. Zupan and J. Gasteiger, Neural Networks for Chemists-An Introduction, VCH, Weinheim (1993).

23. J. Zupan, Acta Chim. Slov., 41, 327 (1994).

24. S. Agatonovic-Kustrin, M. Zecevic and Lj. Zivanovic, J. Pharm. Biomed. Anal., 21, 95 (1999).

25. H.M. Henrique, E.L. Lima and D.E. Seborg, Chem. Eng. Sci., 55, 5457 (2000).

26. Z. Ramadan, X.-H. Song, P.K. Hopke, M.J. Johnson and K.M. Scow, Anal. Chim. Acta, 446, 231 (2001).

27. R.B. Boozarjomehry and W.Y. Svrcek, Comput. Chem. Eng., 25, 1075 (2001).

28. M.S. Chun, J.J. Yi and Y.H. Moon, J. Mater. Process. Technol., 111, 146 (2001).

29. M. Fullana, F. Trabelsi and F. Recasens, Chem. Eng. Sci., 55, 79 (2000).

30. X. Yao, X. Zhang, R. Zhang, M. Liu, Z. Hu and B. Fan, Talanta, 57, 297 (2002).

31. R.C. Pettersen, V.H. Schwandt and M.J. Effland, J. Chromatogr. Sci., 22, 478 (1984)

32. B. Cao, U. Tschirner, S. Ramaswamy and A. Webb, Tappi J., 80, 193 (1997). 